\title{
Brief inhalation of nitric oxide increases resuscitation success and improves 7-day- survival after cardiac arrest in rats: a randomized controlled animal study
}

\author{
Anne Brücken ${ }^{1 *+}$, Matthias Derwall ${ }^{1 \dagger}$, Christian Bleilevens ${ }^{1}$, Christian Stoppe ${ }^{1}$, Andreas Götzenich², Nadine T. Gaisa ${ }^{3}$,
} Joachim Weis ${ }^{4}$, Kay Wilhelm Nolte ${ }^{4}$, Rolf Rossaint ${ }^{1}$, Fumito Ichinose ${ }^{5}$ and Michael Fries ${ }^{6}$

\begin{abstract}
Introduction: Inhaled nitric oxide (iNO) improves outcomes when given post systemic ischemia/reperfusion injury. iNO given during cardiopulmonary resuscitation (CPR) may therefore improve return of spontaneous circulation (ROSC) rates and functional outcome after cardiac arrest (CA).

Methods: Thirty male Sprague-Dawley rats were subjected to 10 minutes of CA and at least 3 minutes of CPR. Animals were randomized to receive either $0(n=10$, Control), $20(n=10,20$ ppm), or $40(n=10,40$ ppm) ppm iNO during CPR until 30 minutes after ROSC. A neurological deficit score was assessed daily for seven days following the experiment. On day 7, brains, hearts, and blood were sampled for histological and biochemical evaluation.

Results: During CPR, 20 ppm iNO significantly increased diastolic arterial pressure (Control: $57 \pm 5.04 \mathrm{mmHg} ; 20$ ppm: $71.57 \pm 57.3 \mathrm{mmHg}, \mathrm{p}<0.046)$ and decreased time to ROSC (Control: $842 \pm 21 \mathrm{~s} ; 20$ ppm: $792 \pm 5 \mathrm{~s},(p=0.02)$ ). Thirty minutes following ROSC, 20 ppm iNO resulted in an increase in mean arterial pressure (Control: $83 \pm 4 \mathrm{mmHg}$; 20 ppm: $98 \pm 4 \mathrm{mmHg}, p=0.035$ ), a less pronounced rise in lactate and inflammatory cytokine levels, and attenuated cardiac damage. Inhalation of $\mathrm{NO}$ at 20 ppm improved neurological outcomes in rats 2 to 7 days after CA and CPR. This translated into increases in 7 day survival (Control: 4; 20 ppm: 10; 40 ppm 6, (p $\leq 0.0520$ ppm vs Control and 40 ppm).
\end{abstract}

Conclusions: Our study revealed that breathing NO during CPR markedly improved resuscitation success, 7-day neurological outcomes and survival in a rat model of VF-induced cardiac arrest and CPR. These results support the beneficial effects of $\mathrm{NO}$ inhalation after cardiac arrest and CPR.

\section{Introduction}

In industrialized countries, sudden cardiac arrest (CA) remains one of the leading causes of death [1]. Despite improvements in pre-hospital care and the introduction of mild therapeutic hypothermia (MTH) [2], mortality rates of out-of-hospital CA victims are still high, although regional variations are often reported $[3,4]$. Survivors frequently suffer from moderate to severe cognitive deficits 3 months post resuscitation $[5,6]$. These poor outcomes are

\footnotetext{
* Correspondence: abruecken@ukaachen.de

${ }^{\dagger}$ Equal contributors

'Department of Anesthesiology, University Hospital RWTH Aachen, Pauwelsstr. 30, 52074 Aachen, Germany

Full list of author information is available at the end of the article
}

mainly attributable to a distinct pathology termed postCA syndrome [7]. Clinically, this syndrome becomes apparent as cerebral and myocardial dysfunction [8], often associated with a pronounced inflammatory response [9] in concert with microvascular alterations $[10,11]$ and adrenal dysfunction $[9,12]$.

The benefits of MTH have recently been questioned in a large study predominantly including patients with ventricular fibrillation and short duration ischemia [13]. Furthermore, in patients with a more severe insult presenting with asystole, MTH is probably even less effective [14]. Currently no pharmacological agent is available to further improve outcomes for CA victims.

\section{Ciomed Central}

(c) 2015 Brücken et al. Open Access This article is distributed under the terms of the Creative Commons Attribution 4.0 International License (http://creativecommons.org/licenses/by/4.0/, which permits unrestricted use, distribution, and reproduction in any medium, provided you give appropriate credit to the original author(s) and the source, provide a link to the Creative Commons license, and indicate if changes were made. The Creative Commons Public Domain Dedication waiver (http://creativecommons.org/publicdomain/zero/1.0/) applies to the data made available in this article, unless otherwise stated. 
Inhaled nitric oxide (iNO) is approved to treat newborn hypoxemia with pulmonary hypertension [15]. In addition, iNO has been used in the intensive care setting as a selective pulmonary vasodilator in patients suffering from acute respiratory distress syndrome and right heart failure [16, 17]. Accumulating evidence of preclinical and clinical studies suggests that iNO also exerts remote effects independent of its local vasodilatory action. Recently, Minamishima and colleagues demonstrated in a murine model that breathing $40 \mathrm{ppm}$ NO starting 1 hour after $\mathrm{CA}$ and cardiopulmonary resuscitation (CPR) markedly improved neurological and myocardial function, and 10-day survival rate [18]. Whether or not administration of iNO during CPR improves resuscitation success rates was not addressed.

To accelerate the pace of translation of this promising treatment into the clinic to improve outcomes after CA, we examined the effects of iNO administered during CPR until 30 minutes after return of spontaneous circulation (ROSC). We hypothesized that iNO increases resuscitation success and improves cerebral and myocardial outcomes, and survival after prolonged CA in rats.

\section{Methods}

The study protocol was approved by the appropriate ethical Institution (Landesamt für Natur, Umwelt und Verbraucherschutz Nordrhein-Westfalen; Recklinghausen; Germany). The experimental procedures were performed according to the Guide for the Care and Use of Laboratory Animals formulated by the National Research Council (National Academies Press, 1996) and the ARRIVE guidelines (National Centre for the Replacement, Refinement and Reduction of animals in research, 2010). In addition, all reported data and outcomes are in accordance with the Utstein style guidelines for uniform reporting of laboratory CPR research [19].

A total of 30 male Sprague-Dawley rats (Charles River, Sulzfeld, Germany) weighing between 400-500 g were investigated in an established rodent CA model [20]. Animals were housed in adequately spaced cages $(60 \mathrm{~cm} \times 40$ $\mathrm{cm}$; type 2000; Tecniplast; Buguggiate; Italy) with a 12hour light-dark cycle. Animals had free access to water and food prior to the study.

Two different concentrations of iNO (20 ppm vs. 40 ppm), administered during CPR until 30 minutes after ROSC, were tested against 0 ppm iNO (control). Primary endpoints were resuscitation rates, and neurological outcome when compared to controls.

\section{Animal preparation}

We used a rat model of CA and CPR as previously described, with minor modifications [20]. On the day of the procedure, rats were anesthetized with an intraperitoneal injection of pentobarbital $\left(45 \mathrm{mg} \cdot \mathrm{kg}^{-1}\right)$.
Additional doses $\left(10 \mathrm{mg} \cdot \mathrm{kg}^{-1}\right)$ of pentobarbital were administered if signs of animal discomfort were noted, i.e., sudden rise in heart rate (HR), respiratory rate, or tail or paw movement. The animals' chests and backs were thoroughly shaved to allow for direct contact of the defibrillator electrodes used for defibrillation during CPR.

After placing the rats on a surgical board in the supine position, the trachea was orally intubated using a modified $14 \mathrm{G}$ cannula (Abbocath-T, Abbott Hospital Division, North Chicago, IL, USA). Animals were mechanically ventilated with a specialized ventilator capable of precise delivery of NO (Servo Ventilator 300A, Siemens, Munich, Germany) with an inspired oxygen fraction $\left(\mathrm{FiO}_{2}\right)$ of 0.3 . Respiratory frequency was adjusted to maintain end-tidal $\mathrm{PCO}_{2}$ between 35 and $40 \mathrm{mmHg}$, continuously monitored using an infrared $\mathrm{CO}_{2}$ analyzer (Cap Star 100, CWE Inc., Ardmore, PA, USA). A three-lead electrocardiogram was continuously measured using monopolar needle electrodes (MLA1204 Needle Electrodes, AD Instuments, Oxford, UK). The left femoral artery was surgically exposed, cannulated with a polyethylene catheter (PE 50) and connected to a high sensitivity transducer (Capto SP 844 Physiologic Pressure Transducer, Capto Inc., Skoppum, Norway) for the measurement of mean and diastolic arterial pressure (MAP and DAP). The left femoral vein was cannulated with an additional PE 50 catheter to allow for administration of fluids and epinephrine during CPR. Rectal temperature was monitored and maintained between 37.0 and $37.5^{\circ} \mathrm{C}$ with the aid of a heating mat (TCAT-2LV-controller, Physitemp Science Products, Hofheim, Germany). All catheters were flushed intermittently with saline solution containing $2.5 \mathrm{IU} \cdot \mathrm{ml}^{-1}$ of heparin.

\section{Experimental procedure}

After preparation, animals were randomly assigned to three groups using the sealed envelope method. Animals received either $20 \mathrm{ppm}(\mathrm{n}=10)$ or $40 \mathrm{ppm}(\mathrm{n}=10)$ iNO, started with initiation of ventilation during $\mathrm{CPR}$ or no iNO treatment (control, $\mathrm{n}=10$ ).

Ventricular fibrillation (VF) was induced by transesophageal electrical stimulation. After placing the electrode using fluoroscopy guidance, alternating current $(10 \mathrm{~V}, 50$ $\mathrm{Hz}$ ) was delivered to the heart using a commercially available fibrillator ( $\mathrm{Fi} 20 \mathrm{M}$, Stockert $\mathrm{GmbH}$, Freiburg, Germany). CA was confirmed by an abrupt decrease in MAP to less than $20 \mathrm{mmHg}$. Simultaneously, ventilation was stopped. After 10 minutes of untreated CA, CPR was initiated including mechanical ventilation with an $\mathrm{FiO}_{2}$ of 1.0 at a respiratory rate of $50 \cdot \mathrm{min}^{-1}$, and chest compressions delivered by a custom made mechanical thumper at a stroke rate of $200 \cdot \mathrm{min}^{-1}$. Animals in the iNO-treated groups were additionally given either $20 \mathrm{ppm}$ or $40 \mathrm{ppm}$ NO until 30 minutes after ROSC. All animals received an 
intravenous bolus of $0.02 \mathrm{mg} \cdot \mathrm{kg}^{-1}$ epinephrine administered via the femoral access 30 seconds after starting chest compressions, which was repeated when MAP fell below $50 \mathrm{mmHg}$. After 3 minutes of CPR, external defibrillation with $5 \mathrm{~J}$ (Zoll MSeries, Zoll Medical Corporation, Chelmsford, MA, USA) was attempted up to three times. If ROSC was not achieved, administration of epinephrine at the same dosage and chest compressions were repeated for 1 minute before additional direct current counter shocks (again up to three times) were delivered. This cycle was repeated up to three times. ROSC was confirmed by spontaneous cardiac rhythm in conjunction with a rise in MAP to greater than $50 \mathrm{mmHg}$. If no ROSC was achieved within 3 minutes after the first shock, resuscitation attempts were stopped. Thirty minutes after successful resuscitation, $\mathrm{FiO}_{2}$ was reduced to 0.3 in all groups, and iNO administration was stopped. Animals were weaned from the ventilator and returned to their cages.

\section{Measurements}

Ischemia time was calculated as the sum of the duration of VF (10 minutes), CPR (3 minutes) and the additional time needed to achieve ROSC (at most 3 additional minutes of CPR). Heart rate, MAP, DAP and end-tidal $\mathrm{CO}_{2}$ were continuously recorded on a multichannel recorder (Power Lab, AD Instruments, Spechbach, Germany). Arterial blood samples were drawn at baseline, 30 minutes, and 1 hour after ROSC. Partial pressure of arterial oxygen $\left(\mathrm{P}_{\mathrm{a}} \mathrm{O}_{2}\right)$ and of carbon dioxide $\left(\mathrm{P}_{\mathrm{a}} \mathrm{CO}_{2}\right)$, glucose, lactate levels and base excess were measured using a conventional blood gas analyzer (ABL700, Radiometer, Copenhagen, Denmark).

At the same time points and on day 7 post arrest, additional blood samples $(0.5 \mathrm{~mL})$ were drawn and centrifuged for 10 minutes at $2500 \times \mathrm{G}$ and $4{ }^{\circ} \mathrm{C}$. The supernatant serum was immediately stored at $-80{ }^{\circ} \mathrm{C}$ for subsequent analysis of tumor necrosis factor-alpha (TNF$\alpha$ ), interleukin (IL)-1ß and IL-6 using a magnetic bead-based multiplex assay (PCYTMAG-3 K, MerckMillipore, Darmstadt, Germany) and a flow cytometrybased analyzer (LUMINEX ${ }^{\circ}$ 100/200TM system, Austin, TX, USA). Migration inhibitory factor (MIF) levels in the serum samples were assessed using a modified mouse/human combination ELISA technique as described previously [21].

\section{Neurological testing \\ Neurological deficit score}

On the 7 days following CPR, neurological performance was evaluated daily by investigators blinded to the animal's treatment using a neurological deficit score (NDS) previously established in an asphyxial CA model [22] and validated by our group [23]. The test consists of six items rep, and coordination. Each item is graded depending on the severity and given a score. The score ranges from 0 (worst neurological impairment) to 500 (no neurological impairment). Deceased animals did not receive a score and were excluded from further analysis.

\section{Histopathology}

Seven days after successful resuscitation, rats were reanesthetized as described above. A midline thoracotomy was performed and the animals were transcardially perfused with $100 \mathrm{~mL}$ of $\mathrm{NaCl} 0.9 \%$.

\section{Neurohistopathology}

After transcardiac perfusion, brains were carefully removed and trans sagitally cut in half. Right hemispheres were post fixed in buffered $4 \%$ paraformaldehyde. Standardized coronal slices were taken at a thickness of $2 \mathrm{~mm}$ resulting in a total of 8 slices per brain. The neocortex, hippocampal CA1 and anterior and posterior CA $3 / 4$ sectors, and basal ganglia were chosen as regions of interest, and analyzed by an experienced neuropathologist blinded to the animal's treatment assignment. Conventional hematoxylin/eosin (HE) and NeuN (Mouse anti-Neuronal Nuclei, monoclonal, Cat \# MAB 377, Millipore, Darmstadt, Germany) staining was performed. A neuronal damage index was semiquantitatively assessed as previously established in this model [20,23]. The proportion of neuronal cells with shrunken and/or hypereosinophilic cytoplasm (HE staining) in combination with a loss of NeuNimmunoreactivity was determined and summarized in a score: $0-5 \%=1 ; 5-10 \%=2 ; 10-20 \%=3 ; 20-30 \%=4$; $30-40 \%=5 ; 40-50 \%=6 ; 50-60 \%=7 ; 60-70 \%=8 ; 70-$ $80 \%=9 ; 80-90 \%=10$; and $90-100 \%=11$. Additionally activation of caspase 3 was assessed by immunohistochemistry using a rabbit monoclonal antibody against cleaved caspase 3 (Rabbit anti-cleaved Caspase-3 (Asp175), monoclonal, Cat \# 9664, Cell Signaling Technology, Danvers, MA, USA) according to the protocol recommended by the manufacturer. Brain slices from an animal 6 hours after induction of subarachnoid hemorrhage served as positive control for the staining [24]. Animals not surviving until day 7 were excluded from histopathological analysis.

\section{Myocardial histopathology}

After transcardial perfusion, the hearts were gently removed and transversally bisected. Both atria and remnants of the aortic arch were removed, before fixation in $4 \%$ buffered formalin for at least 24 hours. After paraffin embedding, standardized cross-sections of the ventricular parts were taken at a thickness of $2 \mu \mathrm{m}$ resulting in a total of 10 slices per heart. Luxol fast blue (LFB) staining and counterstaining with nuclear fast red was performed according to a standard protocol [25]. Planimetric analysis was performed by two blinded investigators, and 
validated by an experienced pathologist, using ImageJ software (version 1.46r, National Institutes of Health, Bethesda, MD, USA). LFB positive controls (infarcted rat hearts) were used to calibrate the software to a threshold value for the detection of blue color (blue transverse banding and diffuse blue myocytes) to distinguish myofibrillar degeneration (LFB, blue), and normal tissue (nuclear fast red, purple). The values for the planimetric analysis of the two experimenters were averaged and tissue damage was expressed as percentage of blue staining from the total area.

\section{Statistical analysis}

All data are expressed as mean \pm standard error of the mean (SEM). Continuous data were analyzed using unpaired two-way repeated measures analysis of variance (ANOVA) with the Tukey post hoc test. Parameters at distinct time points were tested for significant differences between the groups by two-way ANOVA with the Tukey correction. Differences in survival rates were analyzed by the log-rank test followed by post hoc analysis with the log rank Bonferroni correction. Statistical analyses were performed using IBM SPSS statistic 20 and GraphPad Prism 6.04 (GraphPad Software Inc.) with a two-tailed hypothesis. In all cases, a $p$ value $\leq 0.05$ was considered to indicate statistical significance. On the basis of data derived from pilot experiments, power and sample size calculations were performed using PS: Power and Sample Size Calculation version 2.1.31 software by Dupont and Plummer [26].

\section{Results}

Application of $20 \mathrm{ppm}$ iNO significantly increased DAP during CPR (Fig. 1) and significantly decreased time to ROSC in comparison to untreated controls (20 ppm: $792 \pm 5$ s vs. 40 ppm: $798 \pm 9$ s vs. control: $842 \pm 21$ s; $p=0.0220 \mathrm{ppm}$ vs. control). This translated into pronounced increases in ROSC rates (control: $n=7,20$ ppm: $\mathrm{n}=10,40 \mathrm{ppm} \mathrm{n}=6$ ) and significant differences in the 7-day survival in comparison to animals receiving no iNO treatment (Fig. 2).

There were no significant differences in the number of doses of epinephrine during CPR between groups of animals achieving ROSC (20 ppm: $1.14 \pm 0.3$ vs. 40 ppm: $1.75 \pm 0.3$ vs. control: $2.29 \pm 0.5)$.

No significant differences were observed in hemodynamics, variables of gas exchange, or glucose and lactate concentrations, between iNO-treated animals and the control group at baseline (Table 1, Fig. 3). In control animals, we observed a transient decrease in MAP with a dramatic increase in lactate and glucose levels following ROSC. While both iNO-treated groups presented with higher MAP, lower lactate levels and concurrently higher base excess post ROSC, we only observed a statistically

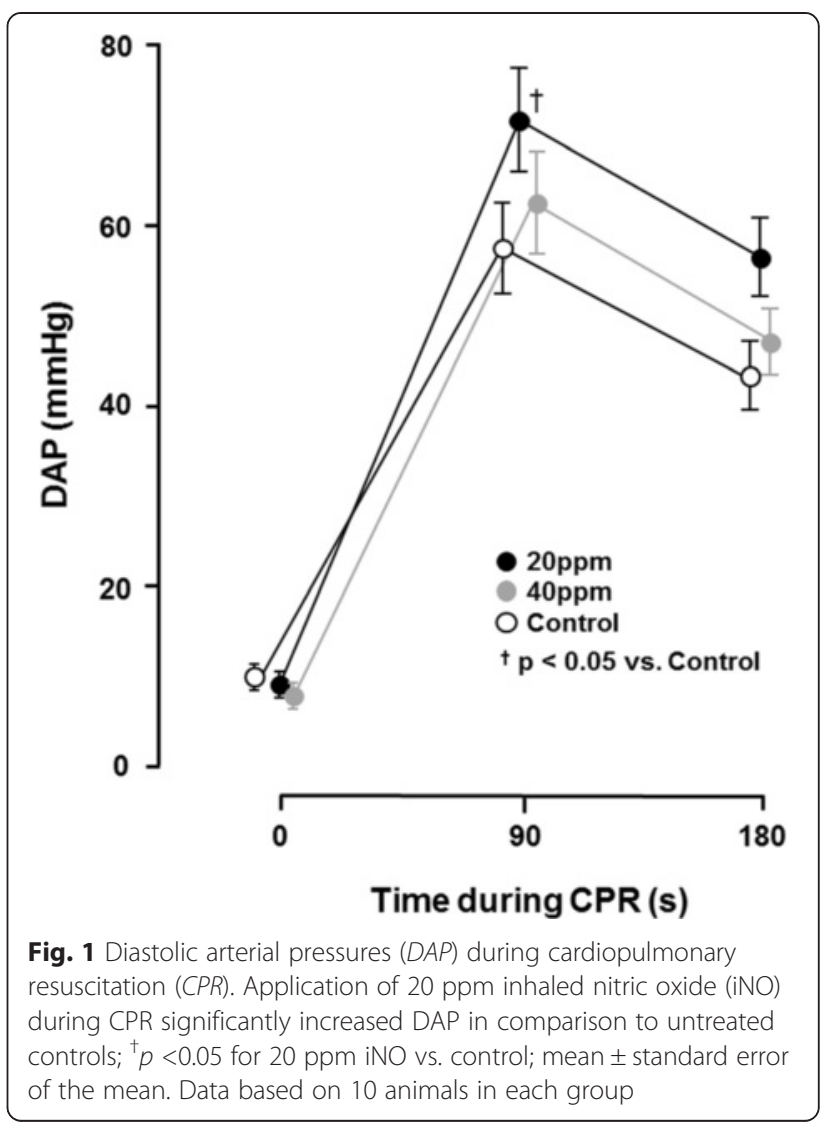

significant difference for these parameters in 20-ppmtreated animals versus controls (Fig. 3). Furthermore, inhalation of $\mathrm{NO}$ attenuated the frequently observed increase in glucose levels after ROSC, however this was not statistically significant.

Successfully resuscitated animals exhibited an increased release of MIF and TNF- $\alpha$, which was reduced by inhalation of NO (Fig. 4). IL-1ß and IL-6 levels were below detection levels of the magnetic bead-based multiplex assay (IL1-ß 2,4 - $10.000 \mathrm{pg} / \mathrm{mL}$; IL-6 73,2 - $30.000 \mathrm{pg} / \mathrm{mL}$ ) at the given time points.

We observed severe neurological dysfunction as measured with the NDS in all control animals during the 7 days after CA and CPR. In contrast, 20 ppm iNO markedly improved neurological function 2-7 days after CA and CPR (Table 2).

Neurohistopathological evaluation revealed that 40 ppm iNO attenuated the neocortical injury in surviving rats 7 days after CA and CPR (Table 3, Fig. 5a-d). There was no difference between treatment groups in the extent of histological brain injury in other regions of the brain. We did not observe caspase-3 activation in brain sections from any of the groups 7 days after CA (Fig. 6).

We observed that $\mathrm{CA}$ and $\mathrm{CPR}$ caused myocardial damage in control rats as demonstrated by LFB staining 


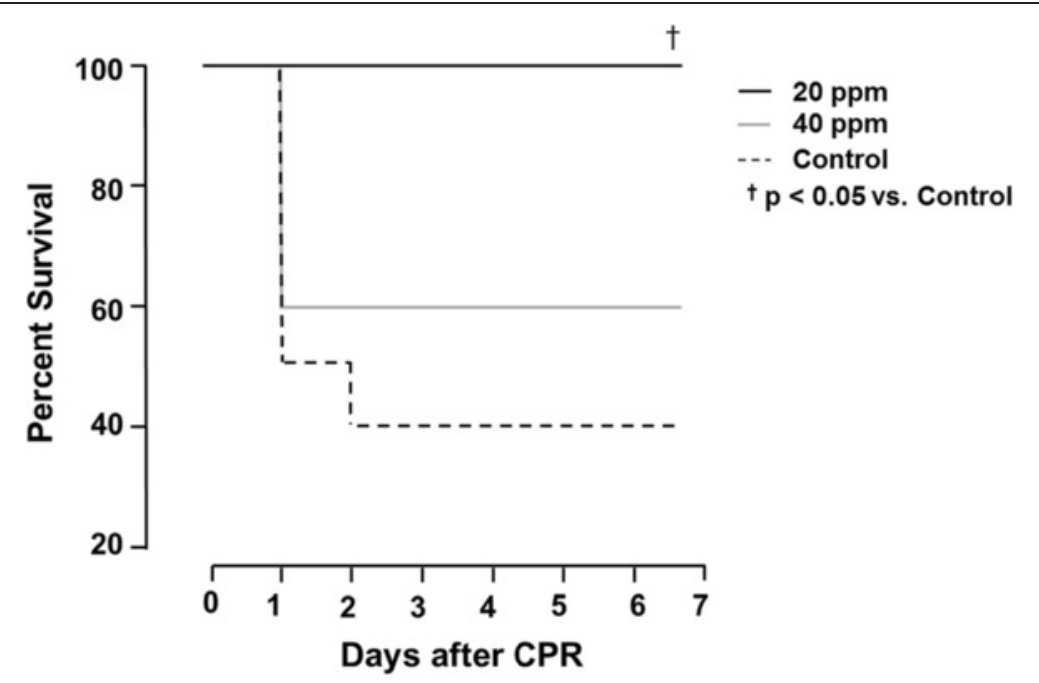

Fig. 2 Seven-day survival in all groups. Animals treated with 20 ppm inhaled nitric oxide (iNO) had significantly better 7 day survival in comparison to control animals; ${ }^{\dagger} p<0.05$ for 20 ppm iNO vs. control. CPR cardiopulmonary resuscitation

which was significantly attenuated by inhalation of 20 ppm NO (Fig. 7a and b).

\section{Discussion}

Our study demonstrates that ventilation with $20 \mathrm{ppm}$ iNO, but not $40 \mathrm{ppm}$ iNO during resuscitation until 30 minutes after ROSC, increases DAP during CPR, resulting in a decreased time to ROSC. The beneficial effects of iNO were associated with higher MAPs, lower lactate levels, and a reduced inflammatory response post ROSC in comparison to control animals. Furthermore, CAinduced cardiac damage was markedly attenuated in animals treated with $20 \mathrm{ppm}$ iNO and brain neocortical injury was ameliorated by $40 \mathrm{ppm}$ iNO. Last, breathing 20 ppm NO improved neurological outcomes and 7-day survival rates in rats.

Our study corroborates previous findings of beneficial effects of iNO on neurological damage and mortality when given after CA in mice [27]. Minamishima and colleagues exposed spontaneously breathing mice for 23 hours to $40 \mathrm{ppm}$ NO starting 1 hour after CPR. They observed marked increases in brain water diffusion in the hippocampus, caudoputamen and cortex, indicative of tissue edema in control animals after CA and CPR. Breathing NO markedly ameliorated brain injury and improved neurological function and 10-day survival rate in mice [18]. The same group recently reported that combining iNO with MTH improved outcomes after CA in mice compared to MTH alone [27]. The current study sought to explore the immediate and delayed effects of iNO given during and after CA. While administration of iNO during CPR may currently be difficult to realize in a clinical setting, in the near future a recently developed novel NO-delivery device may enable administration of
iNO in the field, without the need for cumbersome gas tanks [28].

Several other investigations report beneficial effects of iNO on neurological outcomes in parallel with histopathologic alterations in models of stroke or traumatic brain injury [29-31]. Our study confirms these protective effects of iNO on outcome in the setting of VFinduced CA and CPR in rats, a model that is arguably more clinically relevant than KCL-induced arrest in mice. In our study, the beneficial effects of iNO on the neurological outcome was only partially reflected in the histopathological findings; neocortical injury was ameliorated by iNO at $40 \mathrm{ppm}$, but not at $20 \mathrm{ppm}$. This might be due to the fact that several animals in both the iNO and the control group died during the 7-day observation period, and were therefore unavailable for further histopathologic examination (Fig. 2). It is likely that we did not observe cleaved caspase-3 in the brain sections 7 days after CA because caspase- 3 is activated at earlier time points after ischemic insult [18] (Fig. 6).

The beneficial effects of NO on the brain are likely mediated by several mechanisms. In animal models of stroke in mice and sheep, iNO administration led to significant improvements in both regional cerebral blood flow [31] and microvascular blood flow [29] in the penumbra via cyclic guanosine monophosphate-dependent cerebral vasorelaxation. Alternatively, iNO may attenuate inflammatory response [32]. Recent studies suggested salutary effects of iNO on markers of inflammation and oxidative stress in patients undergoing cardiac surgery [33]. In line with this, our study reveals that $20 \mathrm{ppm}$ iNO significantly attenuates the release of TNF- $\alpha$ and MIF in rats after CA and CPR. MIF is an upstream regulator of the initial immune response with various pro- 
Table 1 Physiologic data

\begin{tabular}{|c|c|c|c|c|}
\hline & & $\mathrm{BL}$ & PR 30 & PR 60 \\
\hline \multirow[t]{3}{*}{ HR (bpm) } & Control & $378 \pm 11$ & $336 \pm 9$ & $364 \pm 20$ \\
\hline & 20 pm iNO & $360 \pm 15$ & $344 \pm 12$ & $372 \pm 15$ \\
\hline & 40 ppm iNO & $389 \pm 9$ & $383 \pm 11$ & $402 \pm 12$ \\
\hline \multirow[t]{3}{*}{$\mathrm{Hgb}(\mathrm{g} / \mathrm{dL})$} & Control & $14.5 \pm 0.2$ & $15.8 \pm 0.4$ & $16.2 \pm 0.5$ \\
\hline & 20 pm iNO & $14.6 \pm 0.3$ & $15.9 \pm 0.2$ & $15.5 \pm 0.4$ \\
\hline & 40 ppm iNO & $14.2 \pm 0.3$ & $15.3 \pm 0.5$ & $15.2 \pm 0.4$ \\
\hline \multirow[t]{3}{*}{ CO-Hba (\%) } & Control & $0.4 \pm 0.1$ & $0.1 \pm 0.1$ & $0.4 \pm 0.1$ \\
\hline & 20 pm iNO & $0.5 \pm 0.1$ & $0.8 \pm 0.3$ & $0.0 \pm 1.1$ \\
\hline & 40 ppm iNO & $0.5 \pm 0.1$ & $0.1 \pm 0.5$ & $0.4 \pm 0.3$ \\
\hline \multirow[t]{3}{*}{ Glucose (mg/dL) } & Control & $139 \pm 5$ & $306 \pm 28$ & $190 \pm 29$ \\
\hline & 20 pm iNO & $129 \pm 5$ & $240 \pm 14$ & $179 \pm 15$ \\
\hline & 40 ppm iNO & $125 \pm 7$ & $204 \pm 16$ & $141 \pm 13$ \\
\hline \multirow[t]{3}{*}{$\mathrm{HCO}^{-}$} & Control & $27.4 \pm 0.3$ & $14.8 \pm 1.7$ & $22.2 \pm 0.1$ \\
\hline & 20 pm iNO & $27.1 \pm 0.4$ & $19.2 \pm 1.0$ & $23.0 \pm 0.4$ \\
\hline & 40 ppm iNO & $26.7 \pm 0.6$ & $18.7 \pm 0.6$ & $22.7 \pm 0.1$ \\
\hline \multirow[t]{3}{*}{$\mathrm{Ph}$} & Control & $7.4 \pm 0.0$ & $7.2 \pm 0.1$ & $7.4 \pm 0.0$ \\
\hline & 20 pm iNO & $7.4 \pm 0.1$ & $7.3 \pm 0.0$ & $7.4 \pm 0.0$ \\
\hline & 40 ppm iNO & $7.4 \pm 0.1$ & $7.3 \pm 0.0$ & $7.4 \pm 0.0$ \\
\hline \multirow[t]{3}{*}{$\mathrm{PaO}_{2}(\mathrm{mmHg})$} & Control & $131 \pm 8$ & $301 \pm 36$ & $121 \pm 5$ \\
\hline & 20 pm iNO & $136 \pm 9$ & $253 \pm 38$ & $122 \pm 11$ \\
\hline & 40 ppm iNO & $124 \pm 6$ & $271 \pm 21$ & $132 \pm 10$ \\
\hline \multirow[t]{3}{*}{$\mathrm{PaCO}_{2}(\mathrm{mmHg})$} & Control & $42 \pm 2$ & $42 \pm 3$ & $41 \pm 3$ \\
\hline & 20 pm iNO & $42 \pm 2$ & $48 \pm 3$ & $40 \pm 2$ \\
\hline & 40 ppm iNO & $41 \pm 1$ & $40 \pm 2$ & $38 \pm 1$ \\
\hline \multirow[t]{3}{*}{ Temperature $\left({ }^{\circ} \mathrm{C}\right)$} & Control & $37.4 \pm 0.1$ & $37.2 \pm 0.2$ & $37.4 \pm 0.1$ \\
\hline & 20 pm iNO & $37.3 \pm 0.1$ & $37.4 \pm 0.1$ & $37.4 \pm 0.1$ \\
\hline & 40 ppm iNO & $37.4 \pm 0.0$ & $37.3 \pm 0.1$ & $37.3 \pm 0.1$ \\
\hline
\end{tabular}

Physiologic data for control and iNO-treated animals at baseline and after cardiopulmonary resuscitation. Temperature indicates body temperature estimated using a rectal probe. ${ }^{*} P<0.05$ vs. control; mean \pm standard error of the mean. Data based on 10 animals in each group on BL. PR30 and PR60: control, $n=7 ; 20$ ppm, $\mathrm{n}=10 ; 40 \mathrm{ppm}, \mathrm{n}=6 . B L$ baseline, $P R$ time post resuscitation in minutes, $H R$ heart rate, $\mathrm{Hgb}$ hemoglobin, $\mathrm{CO}-\mathrm{Hba}$ carboxyhemoglobin in arterial blood, $\mathrm{PaO}_{2}$ arterial oxygen tension, $\mathrm{PaCO}_{2}$ arterial carbon dioxide tension

inflammatory effects [34], which initiates and exacerbates chronic and acute inflammatory disorders [35]. MIF regulates the production and release of TNF- $\alpha$, IL$1 \beta$, IL-2, IL-6, IL-8, IL-12 and interferon (IFN)- $\gamma[34$, 35]. Furthermore MIF has unique characteristics in its rapid release profile in response to pathogenic stimuli (e.g., hypoxia, infection, or inflammation) from several cell types including $\mathrm{T}$ cells, macrophages, endothelial cells, thrombocytes and cardiomyocytes, which is due to its storage in preformed intracellular pools [34, 35]. In the heart, MIF is released by ischemic cardiomyocytes and acts by autocrine/paracrine signaling. Inhibition of MIF pro-inflammatory activities after ischemia has been shown to improve cardiomyocyte survival and myocardial

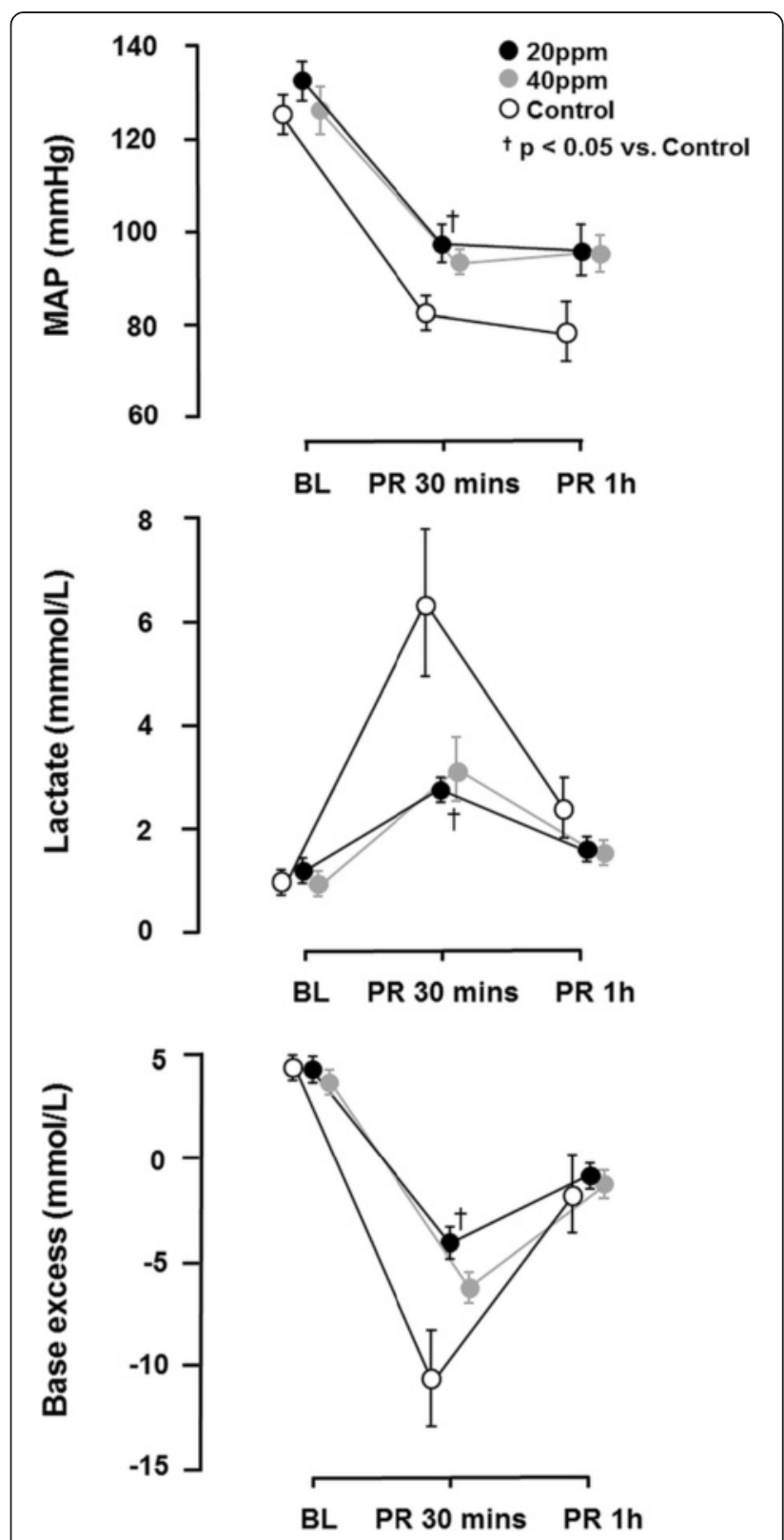

Fig. 3 Alterations in mean atrial pressure (MAP), lactate levels and base excess before cardiac arrest and after return of spontaneous circulation (ROSC). The decrease in MAP and concurrent increase in lactate was significantly less pronounced in animals treated with 20 ppm inhaled nitric oxide (iNO) in comparison to controls. Inhalation of $\mathrm{NO}$ attenuated the decrease in base excess, being significant in animals that received $20 \mathrm{ppm}$ iNO in comparison to controls. ${ }^{\dagger} P<0.05$ for 20 ppm iNO vs. control; mean \pm standard error of the mean. Data based on 10 animals in each group at baseline (BL). All other time points: $20 \mathrm{ppm}, \mathrm{n}=10 ; 40 \mathrm{ppm}, \mathrm{n}=6$; Control, $\mathrm{n}=7$. PR post return of ROSC

function [36, 37]. Therefore, it is suggested that elevated post-ischemic MIF levels exacerbate ischemic tissue damage after myocardial ischemia and reperfusion. [38] Along these lines, our observations suggest that iNO may exert cardioprotective effects after CA 


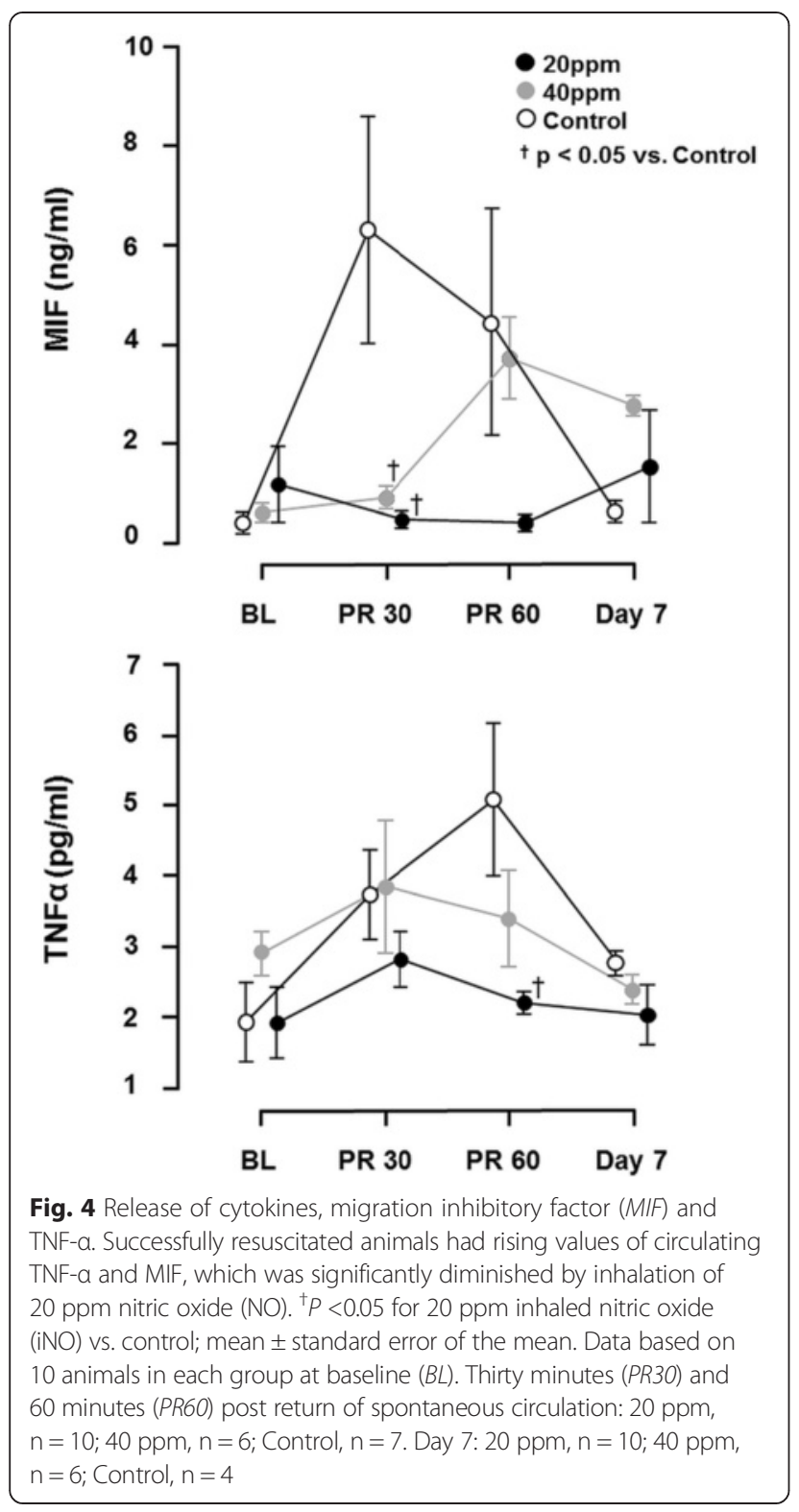

and CPR by inhibiting MIF activity. Additionally, iNO may preserve the blood-brain barrier by preventing apoptosis of cerebral tissue, a mechanism that has been previously described as a driver of cognitive dysfunction after subarachnoid hemorrhage [39].
The protective effects of iNO in our study may also be explained by improved hemodynamics during and after resuscitation. We noted that iNO significantly improved DAP during CPR and this might be a result of increased left ventricular filling. iNO is known to lower pulmonary artery pressure, hence enhancing transpulmonary blood flow. Indeed, dramatic increases in pulmonary artery pressure with concurrent reductions in pulmonary blood flow are well-documented during closed chest compressions in humans and animals [40-42]. Therefore it is conceivable that iNO-induced pulmonary vasodilation improved hemodynamics in our study by enhancing left ventricular filling leading to the improved ROSC rates. In fact, in a recent study in a large animal model of CA and CPR, we observed that iNO markedly decreased pulmonary vascular resistance and increased coronary perfusion pressure [43]. Furthermore, the pulmonary vasodilating effects of iNO might also account for improved hemodynamics and metabolic alterations until 30 minutes post arrest, as we observed significantly higher MAPs, while the arterial lactate level was reduced by almost $100 \%$. Here again, reductions in right ventricular afterload might explain these findings, as right ventricular dysfunction is common in survivors of CA [44].

Inhaled nitric oxide may improve cardiac function via extrapulmonary effects. For instance, iNO has been shown to improve cardiac function not only through unloading the right ventricle (RV) and thus improving left ventricular (LV) preload, but also through direct effects on contractility [45]. Consistent with a previous study by Dezfulian and colleagues, our results showed that iNO markedly attenuated myocardial injury as demonstrated by LFB staining. By its ability to act as an anti-oxidant, iNO may also prevent injury to vascular smooth muscle cells caused by reactive oxygen species [46], and may therefore preserve an adequate vascular tone. Tissue perfusion may furthermore be improved by the ability of iNO to inhibit platelet aggregation [47].

We propose a dual mechanism of action for iNO in the setting of CA and CPR, which first allows for improved resuscitation success by increased left ventricular filling and then exerting secondary actions on cerebral microvasculature and the inflammatory response. While both effects appear to contribute to the pro-survival

Table 2 Neurologic deficit score

\begin{tabular}{llllllll}
\hline & Day 1 & Day 2 & Day 3 & Day 4 & Day 5 & Day 6 & Day 7 \\
\hline Control & $300 \pm 99$ & $308 \pm 104$ & $373 \pm 85$ & $390 \pm 94$ & $390 \pm 94$ & $390 \pm 94$ & $403 \pm 82$ \\
20 pm iNO & $393 \pm 157$ & $473^{*} \pm 43$ & $479^{*} \pm 37$ & $482^{*} \pm 23$ & $485^{*} \pm 24$ & $487^{*} \pm 18$ & $488^{*} \pm 17$ \\
40 ppm iNO & $376 \pm 85$ & $398 \pm 70$ & $430 \pm 54$ & $454 \pm 40$ & $471 \pm 36$ & $463 \pm 43$ & $467 \pm 45$
\end{tabular}

Neurological deficit score on all days following cardiac arrest and cardiopulmonary resuscitation. Control animals exhibited severe neurological dysfunction. Inhaled nitric oxide (iNO)-treated animals had better neurological outcomes, with a statistically significant difference in animals treated with $20 \mathrm{ppm}$ iNO on postoperative days $2-7 ;{ }^{*} p<0.05$ for 20 ppm iNO vs. control; mean \pm SD. Day 1: Control, $n=5 ; 20$ ppm iNO, $n=10 ; 40$ ppm iNO, $n=6$. Days 2-7: Control, $n=4$; $20 \mathrm{ppm}$ iNO, $\mathrm{n}=10 ; 40 \mathrm{ppm}$ iNO, $\mathrm{n}=6$ 
Table 3 Neuronal damage index

\begin{tabular}{llllc}
\hline NDI & Neocortex & CA 1 & CA 3/4 & Basal ganglia \\
\hline Control & $2.25 \pm 0.25$ & $2.00 \pm 0.71$ & $2.50 \pm 1.10$ & $1.00 \pm 0.00$ \\
20 pm iNO & $2.00 \pm 0.15$ & $2.50 \pm 0.50$ & $1.60 \pm 0.31$ & $1.10 \pm 0.10$ \\
40 ppm iNO & $1.60^{*} \pm 0.25$ & $3.20 \pm 1.20$ & $1.60 \pm 0.40$ & $1.00 \pm 0.00$ \\
\hline
\end{tabular}

Conventional hematoxylin/eosin and NeuN (Mouse anti-Neuronal Nuclei) staining was performed. A neuronal damage index $(N D I)$ was semiquantitatively assessed in neocortex, hippocampal CA1 and CA $3 / 4$ sectors. ${ }^{*} P<0.05$ for 40 ppm inhaled nitric oxide (iNO) vs. control mean \pm standard error of the mean. Data based on cerebral tissue taken from Control animals $(n=4)$, and animals treated with 20 ppm $(n=10)$, and $40 \mathrm{ppm}(\mathrm{n}=5)$ iNO

effects of iNO, the hemodynamic effects appear to be more crucial in this particular setting, as optimal hemodynamics during CPR are the prerequisite for ROSC. Additionally, altered tissue perfusion can modify reactions on cellular and sub-cellular levels as a secondary effect. How iNO exerts extrapulmonary effects remains incompletely understood. It has been suggested that $\mathrm{NO}$ is transported to remote organs as more stable bioactive molecules including iron nitrosyl [48], S-nitrosothiols [49], nitrite [50], and nitrosolipids [51]. Previous studies showed that beneficial effects of iNO after CA and CPR were associated with marked increase in serum nitrite levels [18, 27]. Although the exact mechanisms of endocrine effects of $\mathrm{NO}$ remain elusive, the current study supports the hypothesis that iNO exerts extra-pulmonary effects in remote organs after CA and CPR.

In the current study, the most prominent pro-survival effects were observed with $20 \mathrm{ppm}$ iNO, while histological neocortical injury was ameliorated by $40 \mathrm{ppm}$ iNO. This is in contrast to previously published data from Kida and colleagues who found optimal survival rates after $\mathrm{CA}$ in mice using 40 and $60 \mathrm{ppm}$ iNO concomitantly with MTH [27]. These differences might be

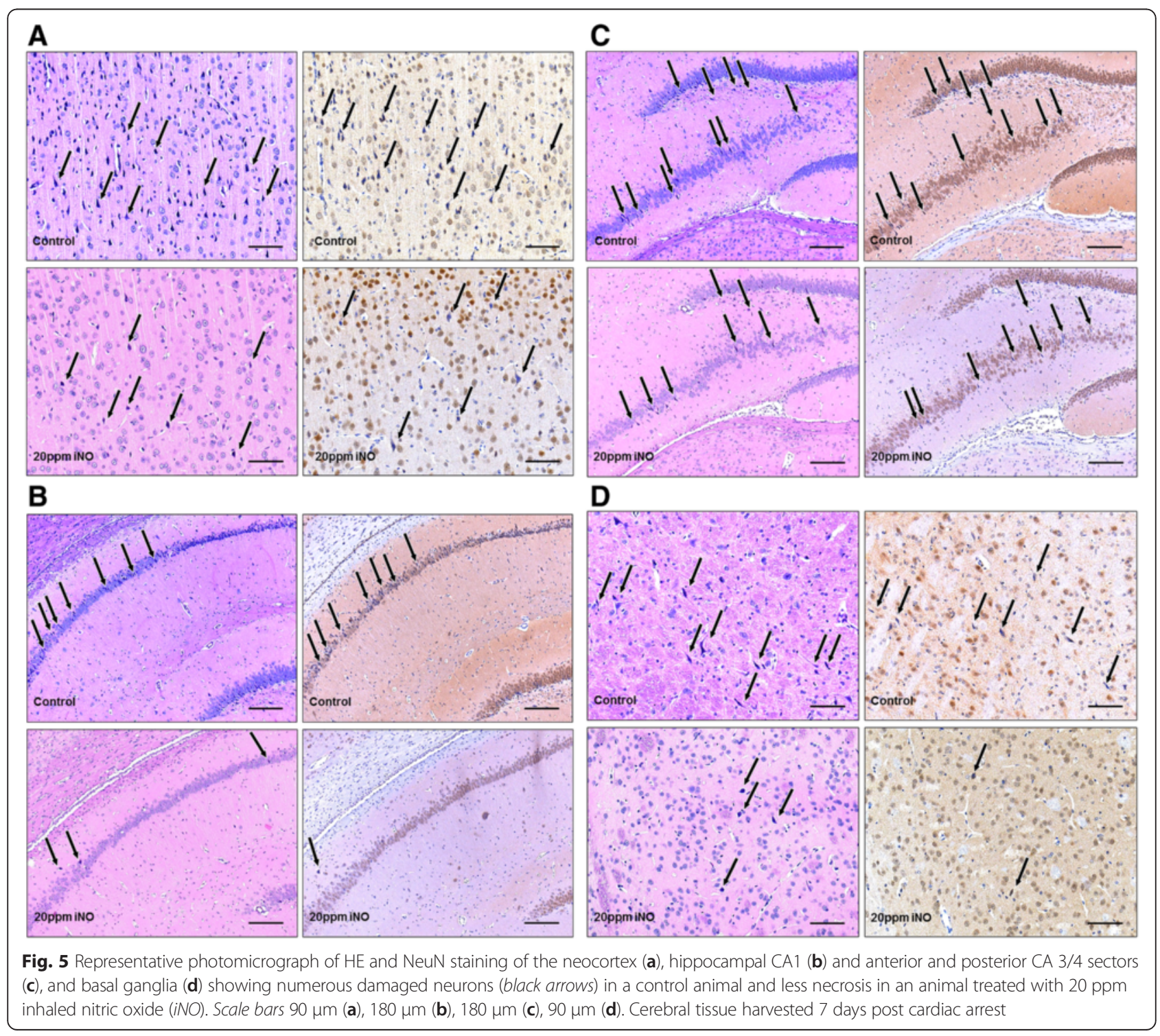



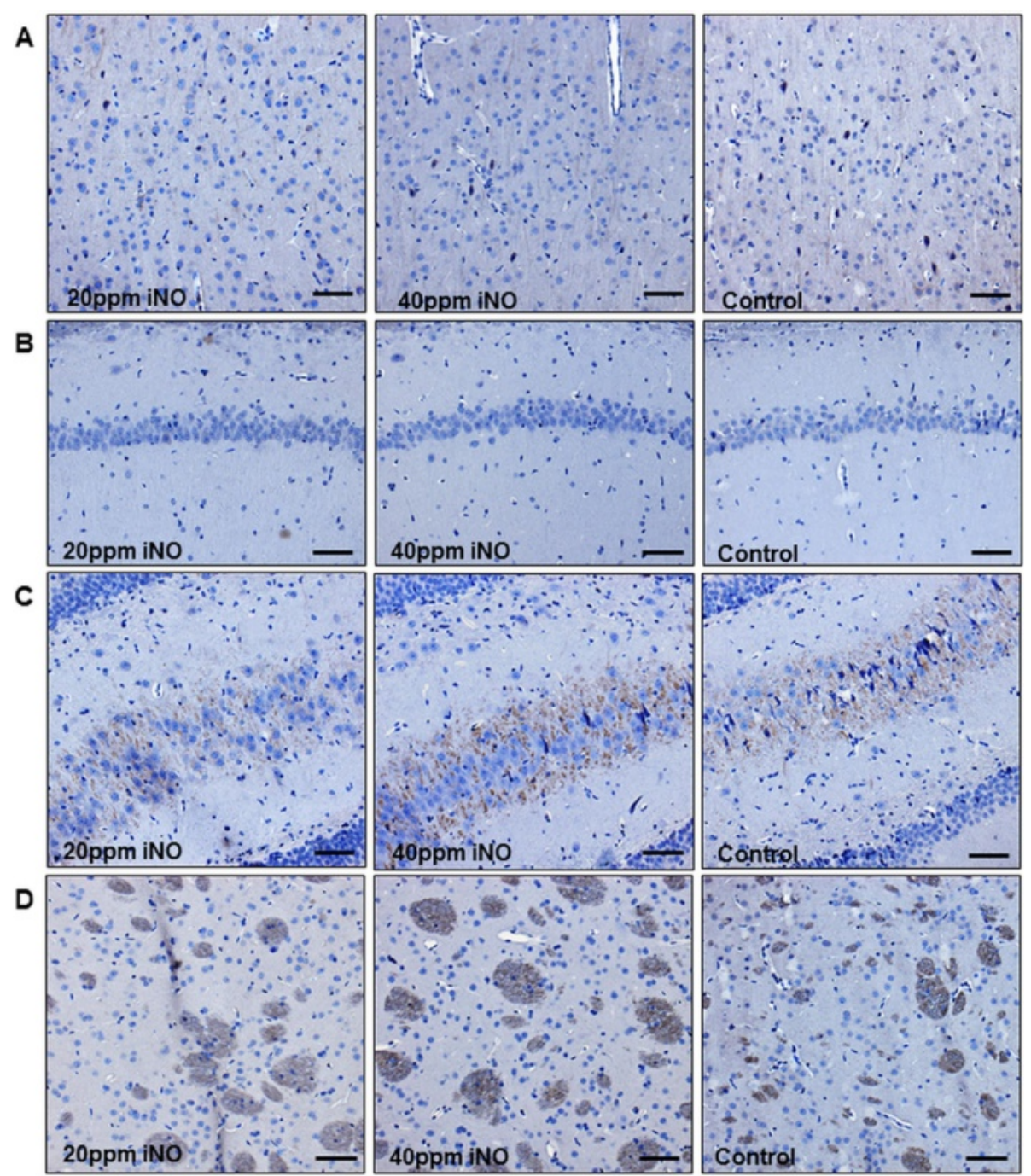

E

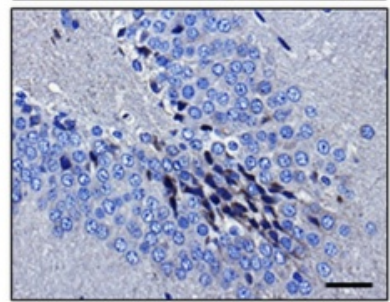

Fig. 6 Representative photomicrograph of immunohistochemical staining for cleaved caspase 3 of the neocortex (a), hippocampal CA1 (b) and anterior and posterior CA 3/4 sectors (c), and basal ganglia (d). No caspase activation was found in any of the groups. Scale bar 90 um. e Gyrus dentatus of an animal 6 hours after induction of subarachnoid hemorrhage as positive control for the staining. Scale bar $30 \mu \mathrm{m}$. Cerebral tissue harvested 7 days post cardiac arrest. iNO inhaled nitric oxide

explained by the different timing of NO inhalation, use of MTH in the Kida study, or limited sample size in both studies. In general, positive effects were observed across a wide range of iNO concentrations $(5-50 \mathrm{ppm})$ in all of the abovementioned investigations [18, 27, 29-31, 52, 53]. The reason why $40 \mathrm{ppm}$ iNO did not improve survival in the current study is unknown at this point. However, it is important to note that iNO at $40 \mathrm{ppm}$ did not worsen survival after CA compared to the air-breathing controls, suggesting that iNO at $40 \mathrm{ppm}$ is not exerting any toxic effects. While breathing very high concentrations of $\mathrm{NO}(\geq 80 \mathrm{ppm})$ at the time of reperfusion may exert toxic effects, presumably by increasing peroxinitrite [31], it has never been observed at 40 ppm iNO in a large number of preclinical and clinical studies [54]. 

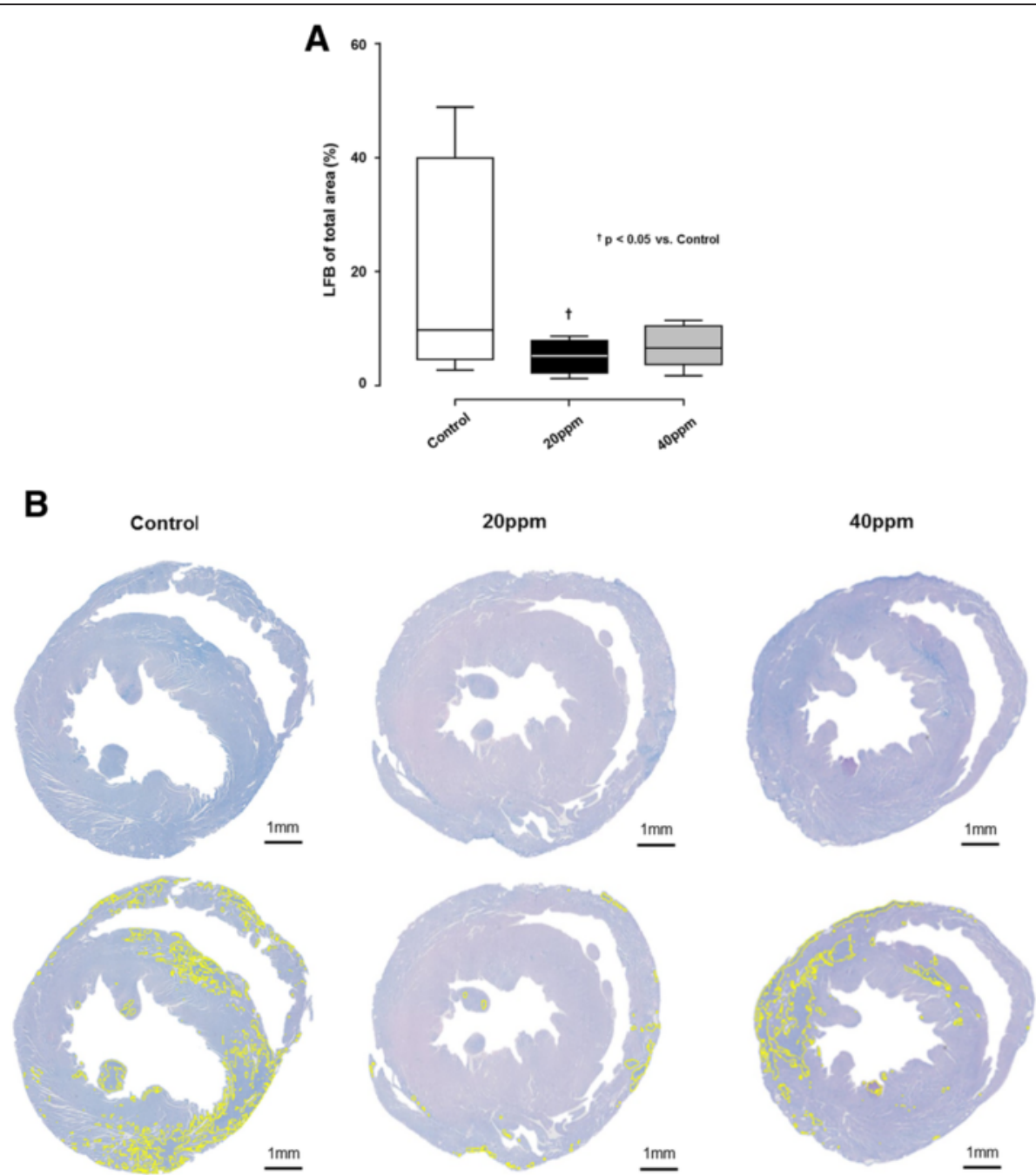

Fig. 7 Successful cardiopulmonary resuscitation resulted in cardiac myofibrillar degeneration detected by luxol fast blue staining (LFB). Cardiac tissue harvested 7 days post cardiac arrest. a Cardiac damage was significantly less pronounced in animals treated with 20 ppm inhaled nitric oxide (iNO) in comparison with untreated controls. Box: bottom and top represent the first and third quartiles, band represents the median, whiskers mark the minimum and maximum of the data. ${ }^{\dagger} P<0.05$ for 20 ppm iNO vs control. Control, $n=4 ; 20$ ppm, $n=10 ; 40$ ppm, $n=6$. b Representative photomicrographs of heart cross-sections with LFB and hematoxylin/eosin (HE) counterstaining of a control, and from a 20-ppm, or 40-ppm iNO-treated animal. The planimetry analysis with imageJ software discriminates between myofibrillar degeneration (LFB blue staining, yellow markers) and undamaged tissue (HE counterstaining, purple)

We recognize several limitations in the interpretation of our findings. First, data were obtained from healthy animals, and translation of results to humans with preexisting diseases has always to be performed with caution. Second, it might well have been that iNO also influenced plasma cytokine levels of IL-1ß and IL6, which we did not detect in our short time frame until 1 hour post CA. Third, post-resuscitation care was not provided in our protocol, possibly resulting in premature death of animals in the control and 40-ppm iNO groups. Having additional survivors on day 7 might have very well influenced the results. However, early neurologic failure is the most common mode of death in humans [55]. As CA was electrically induced in this model, deaths in the early post-resuscitation phases may be the result of cardiovascular collapse rather than pure neurocognitive dysfunction [56]. However, as deceased animals were excluded from further neurocognitive evaluation, this uncertainty did not affect the results of the NDS-based neurocognitive evaluation. As stated above, our study cannot discern whether the effects on hemodynamic function and neurologic outcomes are solely attributable to direct effects of iNO at a cellular level or whether improved myocardial performance resulted in better organ perfusion, which in turn resulted in improved functional recovery. We believe both alterations act in concert to achieve the benefits of iNO during CPR seen in this investigation. Although central venous pressure measurements may 
provide further information, we chose to minimize trauma to optimize our model for the examination of the effects of iNO on long-term neurological outcomes.

\section{Conclusions}

We conclude that $20 \mathrm{ppm}$ iNO administered at the onset of CPR and continued for 30 minutes after successful resuscitation led to increased CPR success and improved 7 -day survival in rats. In addition, the inflammatory response and cardiac damage were attenuated, and neurological performance was significantly improved by $\mathrm{NO}$ inhalation. Although $40 \mathrm{ppm}$ iNO attenuated histological neocortical injury after $\mathrm{CA}$, it did not improve survival rates and neurological function compared to air. It is important to note that $20 \mathrm{ppm}$ is the standard starting concentration of iNO in vast majority of clinical settings. Thus, our findings that breathing $\mathrm{NO}$ at $20 \mathrm{ppm}$ for a short period of time during CPR markedly improves longterm outcomes after CA is highly clinically relevant. These findings should encourage clinical evaluation of iNO, given the well-known and established safety profile of $\mathrm{NO}$ inhalation in adult and pediatric patients. Additional large-animal studies are also warranted to elucidate the mechanisms responsible for the beneficial effects of inhaled NO.

\section{Key messages}

- 20 ppm of iNO increases CPR success and survival

- 20 ppm of iNO improves clinical outcomes after CPR in rats

- Given the well-known and established safety profile of NO inhalation in adult and pediatric patients, these findings should encourage clinical evaluation

\begin{abstract}
Abbreviations
ANOVA: analysis of variance; CA: cardiac arrest; CPR: cardiopulmonary resuscitation; DAP: diastolic arterial pressure; ELISA: enzyme-linked immunosorbent assay; $\mathrm{FiO}_{2}$ : inspired oxygen fraction; HE: hematoxylin/eosin; HR: heart rate; IFN: interferon; IL: interleukin; iNO: inhaled nitric oxide; LFB: Luxol fast blue; MAP: mean arterial pressure; MTH: mild therapeutic hypothermia; MIF: migration inhibitory factor; NDS: neurological deficit score; NDI: neuronal damage index; TNF-a: tumor necrosis factor-alpha; $\mathrm{PaCO}_{2}$ : arterial carbon dioxide tension; $\mathrm{P}_{\mathrm{a}} \mathrm{O}_{2}$ : arterial oxygen tension; ROSC: return of spontaneous circulation; SEM: standard error of the mean; VF: ventricular fibrillation.
\end{abstract}

\section{Competing interests}

The authors declare that they have no competing interests.

\section{Authors' contributions}

$A B$ conceived of the study and its design, carried out the experiments, participated in the data acquisition, analyzed and interpreted the data and drafted the manuscript. MD participated in the design of the study, helped to perform the experiments, analyzed and interpreted the data and drafted the manuscript. Both $A B$ and $M D$ contributed equally to this study. $C B$ carried out the experiments, helped to perform the magnetic bead-based multiplex assays, participated in the data acquisition, helped to analyze the data and revised the manuscript. CS participated in the data acquisition, helped to interpret the data and revised the manuscript critically. AG participated in the data acquisition, helped to interpret the data and revised the manuscript critically. NG prepared the cardiac tissue for examination, performed the myocardial histopathological analysis, discussed the results and revised the manuscript critically. KN prepared the cerebral tissue for examination, performed the neurohistopathological analysis, discussed the results and revised the manuscript. JW, RR and FI participated in the study design, helped to interpret the data and revised the manuscript critically. MF conceived of the study, participated in its design and coordination, analyzed and interpreted the data and helped to revise the manuscript. All authors read and approved the final manuscript.

\section{Author details}

'Department of Anesthesiology, University Hospital RWTH Aachen, Pauwelsstr. 30, 52074 Aachen, Germany. ' Department of Thoracic, Cardiac and Vascular Surgery, University Hospital RWTH Aachen, Pauwelsstr. 30, 52074 Aachen, Germany. ${ }^{3}$ Institute of Pathology, University Hospital RWTH Aachen, Pauwelsstr. 30, 52074 Aachen, Germany. ${ }^{4}$ Institute for Neuropathology, University Hospital RWTH Aachen, Pauwelsstr. 30, 52074 Aachen, Germany. ${ }^{5}$ Anesthesia Center for Critical Care Research, Department of Anesthesia, Critical Care, and Pain Medicine, Massachusetts General Hospital and Harvard Medical School, 55 Fruit Street, Boston, MA 02114, USA. ${ }^{6}$ Department of Anesthesiology, St. Vincenz Hospital Limburg, Auf dem Schafsberg, 65549 Limburg, Germany.

Received: 15 July 2015 Accepted: 4 November 2015

Published online: 17 November 2015

\section{References}

1. Go AS, Mozaffarian D, Roger VL, Benjamin EJ, Berry JD, Blaha MJ, et al. Heart disease and stroke statistics-2014 update: a report from the American Heart Association. Circulation. 2014;129:e28-e292.

2. Peberdy MA, Callaway CW, Neumar RW, Geocadin RG, Zimmerman JL, Donnino M, et al. Part 9: post-cardiac arrest care: 2010 American Heart Association Guidelines for Cardiopulmonary Resuscitation and Emergency Cardiovascular Care. Circulation. 2010;122:S768-786.

3. Wang HE, Devlin SM, Sears GK, Vaillancourt C, Morrison LJ, Weisfeldt M, et al. Regional variations in early and late survival after out-of-hospital cardiac arrest. Resuscitation. 2012;83:1343-8

4. Berdowski J, Berg RA, Tijssen JG, Koster RW. Global incidences of out-of-hospital cardiac arrest and survival rates: Systematic review of 67 prospective studies. Resuscitation. 2010;81:1479-87.

5. Roine RO, Kajaste $\mathrm{S}$, Kaste M. Neuropsychological sequelae of cardiac arrest. JAMA. 1993;269:237-42.

6. Moulaert VR, Verbunt JA, van Heugten CM, Wade DT. Cognitive impairments in survivors of out-of-hospital cardiac arrest: a systematic review. Resuscitation. 2009:80:297-305.

7. Neumar RW, Nolan JP, Adrie C, Aibiki M, Berg RA, Bottiger BW, et al. Post-cardiac arrest syndrome: epidemiology, pathophysiology, treatment, and prognostication. A consensus statement from the International Liaison Committee on Resuscitation (American Heart Association, Australian and New Zealand Council on Resuscitation, European Resuscitation Council, Heart and Stroke Foundation of Canada, InterAmerican Heart Foundation, Resuscitation Council of Asia, and the Resuscitation Council of Southern Africa); the American Heart Association Emergency Cardiovascular Care Committee; the Council on Cardiovascular Surgery and Anesthesia; the Council on Cardiopulmonary, Perioperative, and Critical Care; the Council on Clinical Cardiology; and the Stroke Council. Circulation. 2008;118:2452-83.

8. Laurent I, Monchi M, Chiche JD, Joly LM, Spaulding C, Bourgeois B, et al. Reversible myocardial dysfunction in survivors of out-of-hospital cardiac arrest. J Am Coll Cardiol. 2002:40:2110-6.

9. Adrie C, Adib-Conquy M, Laurent I, Monchi M, Vinsonneau C, Fitting C, et al. Successful cardiopulmonary resuscitation after cardiac arrest as a "sepsis-like" syndrome. Circulation. 2002;106:562-8.

10. van Genderen ME, Lima A, Akkerhuis M, Bakker J, van Bommel J. Persistent peripheral and microcirculatory perfusion alterations after out-of-hospital cardiac arrest are associated with poor survival. Crit Care Med. 2012:40:2287-94.

11. Donadello K, Favory R, Salgado-Ribeiro D, Vincent JL, Gottin L, Scolletta S, et al. Sublingual and muscular microcirculatory alterations after cardiac arrest: a pilot study. Resuscitation. 2011;82:690-5. 
12. de Jong MF, Beishuizen A, de Jong MJ, Girbes AR, Groeneveld AB. The pituitary-adrenal axis is activated more in non-survivors than in survivors of cardiac arrest, irrespective of therapeutic hypothermia. Resuscitation. 2008:78:281-8.

13. Nielsen $N$, Wetterslev J, Cronberg T, Erlinge D, Gasche $Y$, Hassager $C$, et al. Targeted Temperature Management at 33 degrees $C$ versus 36 degrees $C$ after Cardiac Arrest. N Engl J Med. 2013;369:2197-206.

14. Dumas F, Grimaldi D, Zuber B, Fichet J, Charpentier J, Pene F, et al. Is hypothermia after cardiac arrest effective in both shockable and nonshockable patients?: insights from a large registry. Circulation. 2011;123:877-86

15. Clark RH, Kueser TJ, Walker MW, Southgate WM, Huckaby JL, Perez JA, et al. Low-dose nitric oxide therapy for persistent pulmonary hypertension of the newborn. Clinical Inhaled Nitric Oxide Research Group. N Engl J Med. 2000; 342:469-74.

16. Afshari A, Brok J, Moller AM, Wetterslev J. Inhaled nitric oxide for acute respiratory distress syndrome (ARDS) and acute lung injury in children and adults. Cochrane Database Syst Rev. 2010:CD002787. doi: 10.1002/14651858. CD002787.pub2

17. Garg A, Vignesh C, Singh VK, Ray S. Acute right heart syndrome: rescue treatment with inhaled nitric oxide. Indian J Crit Care Med. 2014;18:40-2

18. Minamishima S, Kida K, Tokuda K, Wang H, Sips PY, Kosugi S, et al. Inhaled nitric oxide improves outcomes after successful cardiopulmonary resuscitation in mice. Circulation. 2011;124:1645-53.

19. Idris AH, Becker LB, Ornato JP, Hedges JR, Bircher NG, Chandra NC, et al. Utstein-style guidelines for uniform reporting of laboratory CPR research. A statement for healthcare professionals from a Task Force of the American Heart Association, the American College of Emergency Physicians, the American College of Cardiology, the European Resuscitation Council, the Heart and Stroke Foundation of Canada, the Institute of Critical Care Medicine, the Safar Center for Resuscitation Research, and the Society for Academic Emergency Medicine. Resuscitation. 1996;33:69-84.

20. Brücken A, Cizen A, Fera C, Meinhardt A, Weis J, Nolte K, et al. Argon reduces neurohistopathological damage and preserves functional recovery after cardiac arrest in rats. Br J Anaesth. 2013;110:i106-112.

21. Goetzenich A, Kraemer S, Rossaint R, Bleilevens C, Dollo F, Siry L, et al. The role of macrophage migration inhibitory factor in anesthetic-induced myocardial preconditioning. PLoS One. 2014;9:e92827.

22. Neumar RW, Bircher NG, Sim KM, Xiao F, Zadach KS, Radovsky A, et al. Epinephrine and sodium bicarbonate during CPR following asphyxial cardiac arrest in rats. Resuscitation. 1995;29:249-63.

23. Brücken A, Kurnaz P, Bleilevens C, Derwall M, Weis J, Nolte K, et al. Dose dependent neuroprotection of the noble gas argon after cardiac arrest in rats is not mediated by K(ATP)-channel opening. Resuscitation. 2014:85:826-32

24. Höllig A, Weinandy A, Nolte K, Clusmann H, Rossaint R, Coburn M. Experimental subarachnoid hemorrhage in rats: comparison of two endovascular perforation techniques with respect to success rate, confounding pathologies and early hippocampal tissue lesion pattern. PLoS One. 2015;10:e0123398.

25. Arnold G, Kaiser C, Fischer R. Myofibrillar degeneration-a common type of myocardial lesion and its selective identification by a modified luxol fast blue stain. Pathol Res Pract. 1985;180:405-15.

26. Dupont WD, Plummer Jr WD. Power and sample size calculations for studies involving linear regression. Control Clin Trials. 1998;19:589-601.

27. Kida K, Shirozu K, Yu B, Mandeville JB, Bloch KD, Ichinose F. Beneficial effects of nitric oxide on outcomes after cardiac arrest and cardiopulmonary resuscitation in hypothermia-treated mice. Anesthesiology. 2014;120:880-9.

28. Yu B, Muenster S, Blaesi AH, Bloch DB, Zapol WM. Producing nitric oxide by pulsed electrical discharge in air for portable inhalation therapy. Sci Transl Med. 2015;7:294ra107.

29. Terpolilli NA, Kim SW, Thal SC, Kataoka H, Zeisig V, Nitzsche B, et al. Inhalation of nitric oxide prevents ischemic brain damage in experimental stroke by selective dilatation of collateral arterioles. Circ Res. 2012;110:727-38.

30. Terpolilli NA, Kim SW, Thal SC, Kuebler WM, Plesnila N. Inhaled nitric oxide reduces secondary brain damage after traumatic brain injury in mice. J Cereb Blood Flow Metab. 2013;33:311-8.

31. Charriaut-Marlangue C, Bonnin P, Gharib A, Leger PL, Villapol S, Pocard M, et al. Inhaled nitric oxide reduces brain damage by collateral recruitment in a neonatal stroke model. Stroke. 2012:43:3078-84.
32. Bredt DS, Snyder SH. Nitric oxide: a physiologic messenger molecule. Annu Rev Biochem. 1994;63:175-95.

33. Elahi MM, Worner M, Khan JS, Matata BM. Inspired nitric oxide and modulation of oxidative stress during cardiac surgery. Curr Drug Saf. 2009;4:188-98

34. Calandra T, Roger T. Macrophage migration inhibitory factor: a regulator of innate immunity. Nat Rev Immunol. 2003;3:791-800.

35. Rex S, Kraemer S, Grieb G, Emontzpohl C, Soppert J, Goetzenich A, et al. The role of macrophage migration inhibitory factor in critical illness. Mini Rev Med Chem. 2014;14:1116-24

36. Garner LB, Willis MS, Carlson DL, DiMaio JM, White MD, White DJ, et al. Macrophage migration inhibitory factor is a cardiac-derived myocardial depressant factor. Am J Physiol Heart Circ Physiol. 2003;285:H2500-2509.

37. Chagnon F, Metz CN, Bucala R, Lesur O. Endotoxin-induced myocardial dysfunction: effects of macrophage migration inhibitory factor neutralization. Circ Res. 2005;96:1095-102.

38. Gao XM, Liu Y, White D, Su Y, Drew BG, Bruce CR, et al. Deletion of macrophage migration inhibitory factor protects the heart from severe ischemia-reperfusion injury: a predominant role of anti-inflammation. J Mol Cell Cardiol. 2011;50:991-9.

39. Kreiter KT, Copeland D, Bernardini GL, Bates JE, Peery S, Claassen J, et al. Predictors of cognitive dysfunction after subarachnoid hemorrhage. Stroke. 2002;33:200-8.

40. Swenson RD, Weaver WD, Niskanen RA, Martin J, Dahlberg S. Hemodynamics in humans during conventional and experimental methods of cardiopulmonary resuscitation. Circulation. 1988;78:630-9.

41. Rubertsson S, Wiklund L. Hemodynamic effects of epinephrine in combination with different alkaline buffers during experimental, open-chest, cardiopulmonary resuscitation. Crit Care Med. 1993:21:1051-7.

42. Derwall $M$, Brücken $A$, Bleilevens $C$, Ebeling A, Föhr P, Rossaint $R$, et al. Doubling survival and improving clinical outcomes using a left ventricular assist device instead of chest compressions for resuscitation after prolonged cardiac arrest: a large animal study. Crit Care. 2015;19:123.

43. Derwall M, Ebeling A, Nolte KW, Weis J, Rossaint R, Ichinose F, et al. Inhaled nitric oxide improves transpulmonary blood flow and clinical outcomes after prolonged cardiac arrest: a large animal study. Crit Care. 2015;19:328

44. Meyer RJ, Kern KB, Berg RA, Hilwig RW, Ewy GA. Post-resuscitation right ventricular dysfunction: delineation and treatment with dobutamine. Resuscitation. 2002:55:187-91.

45. Khan SA, Skaf MW, Harrison RW, Lee K, Minhas KM, Kumar A, et al. Nitric oxide regulation of myocardial contractility and calcium cycling: independent impact of neuronal and endothelial nitric oxide synthases. Circ Res. 2003;92:1322-9.

46. El Kebir D, Hubert B, Taha R, Troncy E, Wang T, Gauvin D, et al. Effects of inhaled nitric oxide on inflammation and apoptosis after cardiopulmonary bypass. Chest. 2005:128:2910-7.

47. Beghetti M, Sparling C, Cox PN, Stephens D, Adatia I. Inhaled NO inhibits platelet aggregation and elevates plasma but not intraplatelet cGMP in healthy human volunteers. Am J Physiol Heart Circ Physiol. 2003;285:H637-642.

48. Basu S, Grubina R, Huang J, Conradie J, Huang Z, Jeffers A, et al. Catalytic generation of $\mathrm{N} 2 \mathrm{O} 3$ by the concerted nitrite reductase and anhydrase activity of hemoglobin. Nat Chem Biol. 2007;3:785-94.

49. Ng ES, Jourd'heuil D, McCord JM, Hernandez D, Yasui M, Knight D, et al. Enhanced S-nitroso-albumin formation from inhaled NO during ischemia/reperfusion. Circ Res. 2004;94:559-65.

50. Rassaf T, Totzeck M, Hendgen-Cotta UB, Shiva S, Heusch G, Kelm M. Circulating nitrite contributes to cardioprotection by remote ischemic preconditioning. Circ Res. 2014;114:1601-10.

51. Rubbo H, Parthasarathy S, Barnes S, Kirk M, Kalyanaraman B, Freeman BA Nitric oxide inhibition of lipoxygenase-dependent liposome and low-density lipoprotein oxidation: termination of radical chain propagation reactions and formation of nitrogen-containing oxidized lipid derivatives. Arch Biochem Biophys. 1995;324:15-25.

52. Pham H, Vottier G, Pansiot J, Duong-Quy S, Bollen B, Dalous J, et al. Inhaled NO prevents hyperoxia-induced white matter damage in neonatal rats. Exp Neurol. 2014;252:114-23.

53. Kadar H, Pham H, Touboul D, Brunelle A, Baud O. Impact of inhaled nitric oxide on the sulfatide profile of neonatal rat brain studied by TOF-SIMS imaging. Int J Mol Sci. 2014;15:5233-45. 
54. Ichinose F, Roberts Jr JD, Zapol WM. Inhaled nitric oxide: a selective pulmonary vasodilator: current uses and therapeutic potential. Circulation. 2004;109:3106-11.

55. Laver S, Farrow C, Turner D, Nolan J. Mode of death after admission to an intensive care unit following cardiac arrest. Intensive Care Med. 2004;30:2126-8.

56. Kamohara T, Weil MH, Tang W, Sun S, Yamaguchi H, Klouche K, et al. A comparison of myocardial function after primary cardiac and primary asphyxial cardiac arrest. Am J Respir Crit Care Med. 2001;164:1221-4.

Submit your next manuscript to BioMed Central and take full advantage of:

- Convenient online submission

- Thorough peer review

- No space constraints or color figure charges

- Immediate publication on acceptance

- Inclusion in PubMed, CAS, Scopus and Google Scholar

- Research which is freely available for redistribution 